\title{
Benjamin y Schmitt leen Reflexiones sobre la violencia de Sorel
}

\section{Benjamin and Schmitt read Sorel's Reflections on Violence}

\author{
SEBASTIÁN CHUN*
}

\begin{abstract}
Resumen: En el presente trabajo nos proponemos analizar una vez más los puntos de contacto y las diferencias entre las teorías políticas de Schmitt y Benjamin. Para ello, seguiremos como hilo conductor la lectura que ambos pensadores realizaron del texto Reflexiones sobre la violencia de Sorel. En última instancia, intentaremos dar una respuesta a la pregunta sobre si el mesianismo revolucionario benjaminiano puede ser considerado también una teología política.

Palabras clave: Violencia, Teología, Mesianismo.
\end{abstract}

\begin{abstract}
In this article we aim to analize once again the points of contact and the differences between the political theories of Schmitt and Benjamin. For that purpose, we will follow as a conductive thread the readings they made from the text Reflections on Violence by Sorel. In the last instance, we will attempt to give an answer to the issue if the Benjamin's revolutionary messianism could be considered a political theology, as well.
\end{abstract}

Keywords: Violence, Theology, Messianism.

Es más que abundante la bibliografía dedicada a la relación entre Carl Schmitt y Walter Benjamin. Desde la preocupación "filológica" por desentrañar el orden cronológico de las lecturas y referencias cruzadas ${ }^{1}$ hasta los análisis generales sobre los puntos de contacto y las distancias entre ambos pensadores a lo largo de sus recorridos intelectuales ${ }^{2}$, sigue siendo

Fecha de recepción: 07/06/2014. Fecha de aceptación: 18/02/2015.

* Universidad de Buenos Aires - CONICET. Doctorando e investigador becario. (sebaschun@ hotmail.com). El autor se dedica a investigar el alcance del pensamiento político de Jacques Derrida. Algunas de sus últimas publicaciones han sido "La decisión imposible en Schmitt y Derrida", Res Publica (Murcia), Vol. 17, № 1, 2014, pp. 135-150 y "La democracia por venir como política aporética de la deconstrucción", en Biset, E. y Penchaszadeh A. (comp.), Derrida político, Bs. As., Colihue, 2013, pp. 53-97.

1 Esta cuestión ha sido puesta nuevamente en escena a partir de la hipótesis "invertida" de Agamben, según la cual la teoría de la soberanía de Schmitt sería una respuesta al texto de Benjamin "Para una crítica de la violencia”. Agamben, G., Estado de excepción (Homo Sacer II,1), trad. A. G. Cuspinera, Valencia, Pre-textos, 2004, pp. 79-95. Para una análisis de esta interpretación véase Maura Zorita, E., «Para una lectura crítica de Hacia la crítica de la violencia de Walter Benjamin: Schmitt, Kafka, Agamben», Isegoría. Revista de Filosofía Moral y Política (Madrid), n 41, julio-diciembre 2009, pp. 267-276.

2 Mencionamos aquí sólo algunos de los numerosos textos dedicados a la relación entre Schmitt y Benjamin. Weber, S., «Taking Exception to Decision: Walter Benjamin and Carl Schmitt», Diacritics (Baltimore), Vol. 22, n 3/4, Autumn-Winter 1992, pp. 5-18. Villacañas, J. L. y García, R., «Walter Benjamin y Carl Schmitt: Soberanía y Estado de Excepción», Daimon (Murcia), n 13, Julio-Diciembre 1996, pp. 41-60. Bredekamp, H., «From Walter Benjamin to Carl Schmitt, via Thomas Hobbes», trad. M. Thorson Hause y J. Bond, Criti- 
hoy de gran interés volver a pensar el difícil diálogo entre la teología política y el mesianismo revolucionario ${ }^{3}$. Por esta razón, el propósito de este trabajo será analizar las lecturas que ambos teóricos hacen del texto Reflexiones sobre la violencia de Georges Sorel, en las cuales creemos que se ponen en juego de manera ejemplar sus propios posicionamientos filosóficos, es decir, políticos. En primer lugar, entonces, abordaremos el escrito de Sorel, para así exponer brevemente los puntos centrales de su teoría del mito. Luego, nuestro interés estará puesto en el ensayo Para una crítica de la violencia de Benjamin, el cual tiene una explícita impronta soreliana. Finalmente, nos adentraremos en la lectura de dos textos de Schmitt: La teoría política del mito y Catolicismo y forma política, el primero dedicado en gran parte a la lectura de Sorel y el segundo atravesado por ciertas referencias críticas hacia el pensador francés.

\section{Sorel y el mito de lo político}

El libro Reflexiones sobre la violencia de 1906 es un compilado de artículos que Sorel publicara en la revista Le Mouvement socialiste. En la misma introducción el autor ya manifiesta su anti-liberalismo al declararse pesimista, separándose así del optimismo propio de los economistas. ¿Qué significa para Sorel el pesimismo?

El pesimismo [...] es una metafísica de las costumbres, en mucha mayor medida que una teoría del mundo; es una concepción de un camino hacia la liberación, estrechamente ligado, por una parte, al conocimiento experimental que hemos adquirido de los obstáculos que se oponen a la satisfacción de nuestras ideas [imaginations] (o, si se quiere, ligado al sentimiento de un determinismo social) y, por otra parte, a la convicción profunda de nuestra debilidad natural ${ }^{4}$.

El pesimismo, para Sorel, cuenta entonces con tres aspectos inseparables: el reconocimiento de las fuerzas sociales que forman un sistema impuesto y experimentado como necesario, la posibilidad de la catástrofe como único medio de aniquilación de dicho sistema en bloque y, finalmente, la necesidad de un esfuerzo colectivo para lograr esa liberación. Y allí el primer ejemplo de pesimismo y heroísmo que surge es el cristianismo primitivo, con su lucha por despojarse de la fatalidad satánica y el progreso moral que se sigue como consecuencia de dicha confrontación. El segundo ejemplo histórico se encuentra en el calvinismo del siglo XVI, cuyos representantes realizaban una verdadera revolución catastrófica

cal Inquiry (Chicago), Vol. 25, n², Winter 1999, pp. 247-266. Traverso, E., «"Relaciones peligrosas”. Walter Benjamin y Carl Schmitt en el crepúsculo de Weimar», trad. E. Cohen, Acta Poética (México), Vol. 28, n 1-2, Primavera-Otoño 2007, pp. 93-100. Müller, J-W., «Myth, law and order: Schmitt and Benjamin read reflections on violence», History of European Ideas (Routledge), n 29, 2003, pp. 459-473.

3 Precisamente, parte del debate consiste en calificar o no la concepción benjaminiana de lo político como teología-política. Por lo tanto, en principio, mantenemos esta expresión exclusivamente para la teoría schmittiana de lo político.

4 Sorel, G., Réflexions sur la violence, Paris, Librairie des sciences politiques et sociales, (2a ed.) 1910. Todas las citas, excepto cuando se indica, han sido extraídas de Reflexiones sobre la violencia, trad. F. Trapero, Madrid, Alianza, 1976, pp. 67-68. 
en cada localidad conquistada ${ }^{5}$. Finalmente, Sorel encuentra en la figura del Judío Errante "el símbolo de las más elevadas aspiraciones de la humanidad, siempre condenada a andar sin conocer el descanso"6. Así, esta leyenda sirve de paradigma del héroe que encuentra satisfacción suficiente para alimentar su ánimo en el sentimiento de lucha que acompaña a la voluntad de liberación. Por lo tanto, encontramos aquí ya una clara señal de ateísmo, precisamente al abordar Sorel estas diferentes expresiones monoteístas no en búsqueda de un fundamento metafísico-teológico para una determinada concepción de lo político, sino como instancias donde el anhelo de libertad se actualiza?

Más adelante en el texto, aparece la fundamental distinción que lleva a cabo Sorel entre fuerza y violencia, señalando que la filosofía del derecho natural concuerda perfectamente con la primera. Aquí, el derecho natural es alineado junto al economicismo y el utopismo, en tanto comparten el postulado liberal de que lo justo es aquello que se produce automáticamente en el curso natural de las cosas. Esta crítica al normativismo liberal, en su convicción de que el mero desarrollo automático y natural de las normas resolverá cualquier conflicto, conduce a Sorel a la denuncia de aquellos que "proponen someter los conflictos internacionales a tribunales de arbitraje: esto sería una laicización de la antigua mitología"8. Esa antigua mitología es la del Dios que dirime todas las disputas a favor de quien tiene la razón, volviéndose así el garante de la resolución justa de los enfrentamientos bélicos. Ahora bien, Sorel a continuación señala que los partidarios del derecho natural también afirman que es lícito salirse de la legalidad para recuperar el derecho, principalmente cuando éste se encuentra en manos del adversario, pero jamás desean suprimir el orden de derecho sino utilizarlo en provecho propio. Por el contrario, la violencia proletaria se opone a la fuerza, incluso a la de los socialistas parlamentaristas que buscan establecer una diplomacia normal que permita dirimir los conflictos entre obreros y patronos ${ }^{9}$, en tanto busca anular el derecho y el Estado, núcleo central de aquél. Aquí también surge la crítica a los posibles derechos primordiales de los hombres, los cuales carecen de fundamento una vez que la violencia proletaria se manifiesta y rompe todo pilar sobre el que fundar algún tipo de orden de derecho. ¿Cuál es la diferencia entonces entre la fuerza y la violencia? La primera siempre está conducida a la instauración o conservación de un orden de derecho, mientras que la segunda rompe con el curso natural de las cosas, sin dirigirse teleológicamente (ni teológicamente) hacia una nueva legalidad ${ }^{10}$. Es en este sentido que Sorel, y veremos que con él Benjamin, se interesa por la violencia, no para justificar a los violentos, sino para "saber qué papel le incumbe a la violencia de las masas obreras en el socialismo contemporáneo"11. Al mismo tiempo, señala que no debemos examinar los efectos inmediatos de la violencia, sino sus

5 Op.cit., p. 71.

6 Op.cit., p. 72.

7 Es en este sentido que en Sorel jamás podría haber una teología-política: "ya no tenemos, en la misma medida que nuestros padres, la superstición del Dios-Estado". Op. cit., p. 166.

8 Op.cit., p. 75.

9 Op.cit., p. 130.

10 Vale señalar aquí que la oposición absoluta entre sindicalismo revolucionario y Estado toma en Francia, para Sorel, la forma del antipatriotismo. En este sentido, no se confunden necesariamente Estado, Nación y Patria, aunque cabría preguntarse si es posible para Sorel un mito de lo nacional más allá de la figura Estatal, tal como se desprende de una de las críticas que le realiza Schmitt y que analizaremos más abajo. Op. cit., pp. 172-173.

11 Op.cit., p. 101. 
consecuencias remotas, para así desentrañar la relación entre una violencia actual y la revolución social futura ${ }^{12}$. Aquí, tal vez, se pueda introducir un tercer elemento: el deber. A diferencia del derecho, el cual gracias a su base real en la economía de la producción puede buscar determinaciones rigurosas, el deber se funda en sentimientos como la resignación, la bondad y el sacrificio, siendo así absolutamente indeterminado ${ }^{13}$. Aquellos pacificadores enemigos de la violencia se basan en esta noción de deber, la cual no tiene incumbencia en el plano de la economía. Por lo tanto, los obreros son ajenos a la violencia y consideran a sus patronos como adversarios con los cuales se negocia después de una guerra ${ }^{14}$. Así, afirma Sorel que "no existe el deber social, como tampoco existe el deber internacional"15. De aquí también su llamado a despojar a la violencia de todo prejuicio, cuando afirma que el socialismo, el proletariado, no deben tener vergüenza ni miedo de su barbarie ${ }^{16}$. Leemos en Sorel:

Las violencias proletarias no tienen relación alguna con esas proscripciones; ellas son pura y simplemente actos de guerra, tienen el valor de demostraciones militares y sirven para resaltar la división de clases. Todo lo referente a la guerra se produce sin odio y sin ánimo de venganza; en la guerra no se mata a los vencidos; no se obliga a los seres inofensivos a que soporten las consecuencias de los padecimientos que los ejércitos experimentan en los campos de batalla; la fuerza se despliega en ella con arreglo a su naturaleza, sin pretender nunca recurrir en absoluto a los procedimientos jurídicos que la sociedad aplica contra los criminales ${ }^{17}$.

Hay en la violencia cierta pureza que la libera de la crueldad propia del derecho ${ }^{18}$, que sí está atravesado por cuestiones ajenas a la lucha de clases y que determinan los procedimientos jurídicos como actos de venganza alimentados con ciertas pasiones como el odio o el desprecio

12 Op.cit., p. 102.

13 Incluso aquellos que creen poder fundar el deber en la razón (Kant) se equivocan, ya que ésta siempre nos conduce a preguntarnos si es posible liberarnos de las estrictas obligaciones del deber. Por lo tanto, llegamos a la "comprensión de las elevadas convicciones morales, que no dependen en absoluto de razonamientos o de una educación de la voluntad individual: dependen de un estado de guerra en el cual los hombres aceptan participar, y que se refleja en mitos concretos." Op. cit., p. 283.

14 “...] los socialistas parlamentarios hacen tantos esfuerzos para convencer al público de que ellos tienen almas de pastorcillos sensibles, de que su corazón está henchido de sentimientos de bondad y de que no tienen más que una pasión: el odio hacia la violencia. [...] Para la burguesía contemporánea, todo aquello que descarta la idea de violencia es admirable. Nuestros burgueses desean morir en paz: después de ellos, el diluvio..." Op. cit., pp. 158-159.

15 Op.cit., p. 119.

16 Op.cit., p. 90.

17 Op. cit., p. 171. La traducción ha sido modificada.

18 Véase aquí el claro paralelismo con el formalismo schmittiano a la hora de señalar la distinción amigo-enemigo. El enemigo siempre es público y nunca privado, es decir, su posibilidad está purificada de todo lo que pueda depender de lo individual, psicológico y subjetivo en general. La autonomía de la esfera política implica que cualquier otra distinción (religiosa, moral, estética, económica, etc.) puede alcanzar un grado de intensidad tal que llegue al caso extremo del agrupamiento con base en los conceptos amigo-enemigo, pero una vez que esto sucede lo político domina toda la escena, desapareciendo cualquier otra instancia a partir de la cual se fundamentaría dicha enemistad. Schmitt, C., El concepto de lo político, en Carl Schmitt, teólogo de la política, trad. E. Molina y Vedia y R. Crisafio, México, FCE, 2001. 
hacia los criminales ${ }^{19}$. Si hay barbarie, esta no está del lado de la violencia revolucionaria, pura manifestación de una potencia natural, sino del lado de la ley y su anhelo de justicia ${ }^{20}$.

Y aquí aparece finalmente la figura del mito, en tanto construcción que realizan los hombres que intervienen en los grandes movimientos sociales al "representarse [représentent] su acción inmediata en forma de imágenes de batallas [images de batailles] que conducen al triunfo de su causa" ${ }^{21}$. El ejemplo privilegiado por Sorel es la huelga general de los sindicalistas $^{22}$, que junto a la revolución catastrófica de Marx se suman a los ya mencionados del cristianismo primitivo y la Reforma. En el capítulo dedicado a la huelga proletaria Sorel explicita el carácter "fenomenológico" del mito, en tanto medio de expresión que proyecta sobre las cosas una plena luz, situándolas en el lugar que les ha sido asignado naturalmente y resaltando todo el valor de las fuerzas puestas en juego ${ }^{23}$. El mito, precisamente, logra sacar a relucir las oposiciones ${ }^{24}$.

Cada vez que actuamos damos un paso más allá del presente hacia un porvenir indeterminado e imprevisible. Pero, si bien este futuro escapa a nuestra razón, cuando hablamos de mitos nos encontramos con construcciones de un porvenir indeterminado en el tiempo, que poseen gran eficacia y muy pocos inconvenientes. En los mitos, afirma Sorel,

[...] se manifiestan las más fuertes tendencias de un pueblo, de un partido o de una clase; tendencias que se ofrecen a la mente con la insistencia de instintos en todas las circunstancias de la vida, y que confieren un aspecto de plena realidad a unas esperanzas de acción próxima en las cuales se basa la reforma de la voluntad. ${ }^{25}$

Los mitos son medios de acción sobre el presente, con la mirada puesta en un porvenir inaprehensible y que como tal puede no efectivizarse. Es decir, lo importante del mito no es tanto la perspectiva a futuro que propone sino su incidencia en el aquí y ahora.

A su vez, el mito no tiene que ver con la razón sino con el instinto y los sentimientos que se corresponden con la lucha efectiva contra el orden de cosas vigente ${ }^{26}$. Por lo tanto, el mito de la huelga general tiende a convertir todos los acontecimientos de la vida cotidiana en síntomas de la escisión que atraviesa a la sociedad y que de ninguna manera podrá ser abolida por un mecánico despliegue de las normas en curso $^{27}$.

19 Mientras que la huelga general proletaria está signada por lo "sublime", "cuando los políticos intervienen, suele producirse, y casi de modo necesario, un notable descenso de la moralidad, ya que nada hacen sin algún interés, y solamente obran a condición de que la asociación favorecida pase a engrosar su clientela. Nos encontramos muy lejos aquí del camino hacia lo sublime; antes bien, nos hallamos en el que conduce a los métodos de las sociedades político-criminales". Sorel, G., Reflexiones sobre la violencia, op. cit., p. 287.

20 Para un análisis de la violencia como ajena a la brutalidad véase el capítulo VI. Op. cit. pp. 251-290.

21 Op. cit., p. 77. La traducción ha sido modificada.

22 Para una detallada oposición entre la huelga general proletaria y la huelga general política véase el capítulo V. Op. cit., pp. 216-246.

23 Op.cit., p. 181.

24 Ibid. La traducción ha sido modificada.

25 Op. cit., p. 183.

26 Op. cit., p. 186.

27 Op. cit., p. 193. Aquí resulta relevante mencionar el apéndice I, en el cual Sorel enfrenta la concepción unitaria de la sociedad, perspectiva democrática y economicista basada en una analogía socio-biológica, a la multiplicidad de fuerzas antagónicas que conforman el entramado social. Op. cit., pp. 339-366. 
En cuanto a la tarea del historiador que vuelve su mirada sobre los mitos, Sorel ofrece una aclaración metodológica. Si el sistema formado por las fuerzas sociales que determinan nuestra vida en sociedad y se experimentan como necesarias sólo puede ser combatido cuando se lo toma en bloque, los mitos, en tanto fuerzas que luchan por romper dichas cadenas, comparten esa forma sistemática y, por lo tanto, no pueden ser diseccionados en la mesa de operaciones del analista. A su vez, no hay que superponer el plano de los acontecimientos efectivos con el de las representaciones previas a los mismos. Si bien los mitos orientan las acciones de los hombres, no deben confundirse con éstas; una cosa es la catástrofe imaginada $\mathrm{y}$ otra la que efectivamente llega a romper con el curso natural de las $\operatorname{cosas}^{28}$.

Y aquí aparece una nueva nota característica del pensamiento de Sorel, que se suma a sus ya explicitados pesimismo, ateísmo, marxismo, anti-liberalismo y anti-parlamentarismo: el anti-intelectualismo. Por medio de las religiones como ejemplos de mitos, el pensador francés arguye que la filosofía intelectualista no encuentra aquí un objeto de análisis posible, ya que no puede negar el alcance histórico de los mitos pero tampoco explicarlos, por lo tanto, es impotente ante los grandes movimientos históricos. En el caso puntual de la filosofía burguesa, para ella "la violencia es un residuo de la barbarie, y está llamada a desaparecer bajo la influencia del progreso de la ilustración" ${ }^{29}$. El mito, entonces, tiene que ver con la fe, es decir, con aquello que escapa al cálculo, los argumentos y las discusiones infinitas. En particular, el mito de la huelga general resulta revulsivo para la prudencia intelectualista por su carácter de infinidad, es decir, por entrañar una revolución absoluta. Más allá de la ciencia, en la región de la conciencia profunda, se encuentran para Sorel la religión y los mitos revolucionarios ${ }^{30}$. La pequeña ciencia resulta impotente ante aquello que no se presta a la exposición clara y evidente. El misterio, lo oscuro, lo indeterminado, escapan a la descripción y la reducción a la lógica utilitaria ${ }^{31}$. Bergson aparece, entonces, como el despertar de la filosofía ante una muerte proclamada desde las filas del positivismo. Y es esta filosofía la que servirá de apoyo a Sorel para establecer la distinción entre el yo exterior, condicionado socialmente, y el yo interior, libre de aquellas cadenas sociales.

Para comprender verdaderamente esa psicología, hay que «referirse mediante el pensamiento a esos momentos de nuestra existencia en que hemos optado por una decisión grave [décision grave], momentos únicos en su género y que no se reproducirán, igual que para un pueblo nunca vuelven las fases desaparecidas de su historia.» ${ }^{32}$

¿Podemos hablar de un decisionismo en Sorel? Tal vez sí, al menos si tomamos en cuenta que el instante de la decisión es aquel en que el yo interior logra romper los marcos históricos que lo apresan y construye así un hombre nuevo, gracias a esta manifestación de libertad. La decisión no sigue los lineamientos impuestos por las normas naturales que constituyen el entramado social, sino que interrumpe el desarrollo automático de las mismas y configura

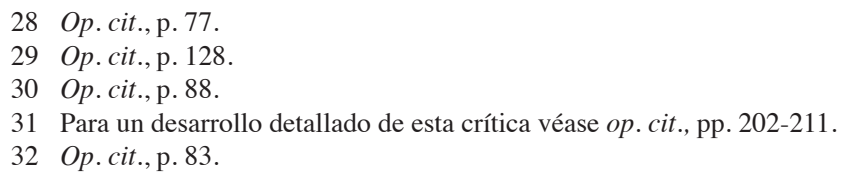


un espacio de libertad ${ }^{33}$. Vale aquí mencionar que el sujeto que hace surgir su yo interior, en el momento que decide lanzarse hacia la lucha por interrumpir el andar mecánico del orden dado, es para Sorel un sujeto colectivo: las masas populares ${ }^{34}$. Ahora bien, acto seguido el pensador francés señala que no es suficiente con decir que nos encontramos dominados por sentimientos soberanos [sentiments souverains], ya que a la hora de hablar de la conciencia creadora hay que hacerlo en términos de movimiento.

Cuando obramos, es porque hemos creado un mundo totalmente artificial situado por delante del presente, y formado por movimientos que dependen de nosotros. Nuestra libertad es, de ese modo, perfectamente inteligible. [...]

Esos mundos artificiales desaparecen por lo general de nuestra mente sin dejar recuerdos; pero cuando las masas se apasionan, entonces cabe describir un cuadro, que constituye un mito social ${ }^{35}$.

El mito no es la descripción de una cosa, sino la expresión de voluntades dispuestas a la lucha decisiva [lutte décisive] que viene a interrumpir, mediante la destrucción de todo lo existente, el normal desarrollo del sistema que regula nuestras vidas ${ }^{36}$. Por el contrario, la utopía, siempre reformista, es un mero producto teórico que presenta analogías con las instituciones reales vigentes y que, en última instancia, puede ser articulado con un nuevo orden de derecho. Uno de los mejores ejemplos de utopía es para Sorel la economía política liberal.

Es fundamental señalar aquí lo que será quizá el punto central de la crítica schmittiana a Sorel. Para el autor francés el capitalismo crea la herencia que recibirá el socialismo y, al mismo tiempo, los medios que llevarán a la destrucción del mundo burgués ${ }^{37}$. En este sentido, existe para Sorel una conservación revolucionaria ${ }^{38}$ (y no una revolución conservadora) en tanto el mundo por venir romperá con el orden dado pero conservará los resultados logrados en el plano de la producción. El capitalismo, entonces, logra producir mecánicamente todo lo necesario para el desarrollo histórico y así da lugar a una nueva era, la cual abandonará el vínculo con la ideología burguesa pero conservará las adquisiciones de la economía capitalista ${ }^{39}$. Es por ello que el capitalismo debe desplegar todo su potencial, desa-

33 "No me conformo a considerar las huelgas como algo análogo a una ruptura temporal de las relaciones comerciales que se produjera entre un tendero y su proveedor de ciruelas pasas debido a que no se ponían de acuerdo en cuanto a los precios. La huelga es un fenómeno bélico". Op. cit., p. 370.

34 En otro pasaje de su texto, refiriéndose a cierta herencia paradójica del código penal francés de su época, Sorel sostiene que "semejante crimen supone que el Estado entero puede ser colocado en situación de peligro por la actuación de una persona: lo cual nos parece escasamente digno de crédito". Op. cit., p. 163. Sin embargo, si bien son las masas las que encarnan la huelga general proletaria, en ésta se manifiesta de la forma más resplandeciente "la fuerza individualista". En este sentido, no hay una disolución del individuo en un sujeto colectivo sino una actualización de su particularidad en la lucha decisiva. Op. cit., p. 323.

35 Op.cit., p. 84.

36 El mito de la gran batalla napoleónica es aquél en el cual los vencidos quedan definitivamente aplastados, dando lugar así a la revolución catastrófica. Op. cit., p. 124.

37 "Marx supone, igual que los sindicalistas, que la revolución será absoluta e irreformable, porque tendrá por efecto el poner las fuerzas productivas en manos de hombres libres, es decir, de hombres capaces de gobernarse, sin necesidad de amos, en el taller creado por el capitalismo." Op. cit., p. 228.

38 Op. cit, p. 150 (nota 5).

39 Op.cit., p. 138. 
rrollar sus formas al máximo, para así nutrir y fortalecer a la fuerza revolucionaria que crece silenciosa en su vientre ${ }^{40}$. Capitalismo y socialismo comparten un suelo común, el cual para Sorel no presentaría en el caso del segundo resabios ideológicos. En otras palabras, cierta forma de producción no estaría directamente ligada al contenido ideológico de la misma ${ }^{41}$. Por eso Sorel puede afirmar que "[...] la huelga general corresponde a unos sentimientos tan vinculados a los que son necesarios para asegurar la producción en un régimen de industria muy progresiva, que el aprendizaje revolucionario puede ser asimismo aprendizaje de productor" 42 . A su vez, señala que tanto el ideal de mediocridad conservadora burgués, que intentaría corregir los abusos de la economía, como la inclinación del proletariado hacia la paz y el corporativismo, frenarían el desarrollo del capitalismo y con él se perdería ese futuro seguro del mundo ${ }^{43}$. La violencia como expresión brutal y clara de la lucha de clases aquí también jugaría un papel indirecto, en tanto actualizaría la conflictividad propia de lo social, recordándoles a los distintos actores cuál es el lugar que ocupan en el entramado histórico ${ }^{44}$. Así, es también responsabilidad del proletariado devolverle a la burguesía su energía, y el medio para dicho fin será por supuesto la violencia, la cual tal vez no produzca mejoras materiales inmediatas, pero sí salvará al mundo de la verdadera barbarie: la liberal ${ }^{45}$.

\section{Benjamin y la violencia divina}

El ensayo Para una crítica de la violencia fue publicado por Benjamin en 192146. Si, para Sorel, la violencia se distinguía tanto de la fuerza propia del derecho y su pretendida búsqueda de justicia como del deber, ya sea racional o sentimentalmente fundamentado, Benjamin, por su parte, comienza señalando que la tarea de una crítica de la violencia se circunscribe "a la exposición de su relación con el derecho (Recht) y con la justicia (Gerechtigkeit)" "47. Desde la perspectiva del derecho, la violencia se encuentra en el dominio de los medios y aquí se suele reducir su crítica a su utilización, según persiga fines justos o injustos, lo cual no es un criterio propio de la violencia como principio, sino un criterio respecto de los casos de su aplicación. Para Benjamin, por este camino “permanecería abierta

40 "La nueva escuela no concibe las cosas fijándose en un modelo idílico, cristiano y burgués, sabe que el progreso de la producción requiere unas cualidades harto diferentes de las que se hallan entre los mundanos; y le preocupa considerablemente la ética por conciencia de los valores morales necesarios para perfeccionar la producción. [...] desearía saber cómo puede crearse hoy la moral de los productores futuros." Op. cit., pp. 303-304. Todo el capítulo sobre la moral de los productores intenta ser una respuesta a esta última pregunta, vinculando la producción a la actividad del artista. Op. cit., pp. 295-331.

41 "Es preciso exponer, de manera que impresione, los vínculos que ligan la revolución con el progreso constante y rápido de la industria.” Op. cit., p. 197.

42 Op.cit., p. 87.

43 Op. cit., p. 140.

44 “"... ] la violencia proletaria encierra a los patronos en su papel de productores, y tiende a restaurar la estructura de las clases a medida que éstas parecían ir entremezclándose en la ciénaga democrática.” Op. cit., p. 142.

45 Op. cit., p. 149.

46 Benjamin, W., "Zur Kritik der Gewalt”,Gesammelte Schriften, II, 1, Frankfurt, Suhrkamp, 1991, pp. $179-203$. Todas las citas, excepto cuando se indica, han sido extraídas de "Para una crítica de la violencia", en Conceptos de filosofía de la historia, trad. H. A. Murena y D. J. Vogelmann, Bs. As., Terramar, 2007, pp. 113-138.

47 Op. cit., p. 113. 
la cuestión de si la violencia en general, como principio, es moral"48, por lo cual es preciso encontrar una distinción dentro de la esfera de los medios que sea independiente de lo justo o no de los fines, abandonando así la justicia como criterio de los mismos, para centrarse en la cuestión de la conformidad a derecho de ciertos medios que abarcan el ámbito de la violencia. Aquí Benjamin introduce su crítica al derecho natural, para el cual el único parámetro para determinar la conformidad a derecho (rechtmäßig) de la violencia será lo justo (gerechten) de sus fines, cuya traducción al dogma de la filosofía del derecho serán los fines naturales ${ }^{49}$. En claro paralelismo con la crítica soreliana al derecho natural, en tanto perspectiva liberal que considera a la norma como sistema mecánico y natural de resolución de conflictos gracias a la producción espontánea de lo justo, para Benjamin tanto el derecho natural como el derecho positivo, para el cual la justicia de los fines se fundamenta en la conformidad a derecho (Rechtmäßigkeit) de los medios, comparten un dogma: "los fines justos (Gerechte) pueden ser alcanzados por medios legítimos (berechtigte), los medios legítimos pueden ser empleados al servicio de fines justos" 50 . El objetivo de Benjamin será entonces demostrar que los medios legítimos y los fines justos son contradictorios entre sí, lo cual implica que se deben encontrar criterios autónomos para cada uno de ellos. La norma, entonces, no produciría en ningún caso lo justo, sino todo lo contrario, lo excluiría de principio. Por esta razón, Benjamin descarta la cuestión de los fines justos, y con ella el derecho natural, pero no así el derecho positivo, el cual será tomado como hipótesis al comienzo de la investigación, en particular la distinción que propone entre una violencia sancionada y una no-sancionada ${ }^{51}$. Ahora bien, sólo la filosofía de la historia nos permitirá, según Benjamin, encontrar un criterio para dicha distinción realizada por el derecho positivo $^{52}$. Y aquí se desliza nuevamente la cuestión de los fines, en tanto

[...] el reconocimiento de violencias jurídicas (Rechtsgewalten) se expresa en la forma más concreta mediante la sumisión pasiva - como principio- a sus fines, como criterio hipotético de subdivisión de los diversos tipos de violencia (Gewalten) es preciso suponer la presencia o la falta de un reconocimiento histórico universal de sus fines ${ }^{53}$.

Para determinar si una violencia está o no sancionada debemos tomar como referencia la obediencia automática hacia los fines que propone o la ausencia de un reconocimiento histórico de los mismos. Los primeros serán los fines de derecho y los segundos los fines naturales, y por supuesto que aquí ya no juega ningún papel el concepto de justicia. Ambos fines entrarán en colisión cada vez que la satisfacción de los naturales implique la utilización de la violencia, ya que para el derecho la violencia en manos de personas individuales constituye un peligro para el orden legal (Rechtsordnung). Es por ello que éste reemplaza los fines naturales que personas aisladas podrían alcanzar mediante la violencia por fines

48 Ibid.

49 Op.cit., p. 114.

50 Ibid.

51 Op.cit., p. 115.

52 Op.cit., p. 116.

53 Ibid. La traducción ha sido modificada. 
de derecho que sólo pueden realizarse por la violencia jurídica, incluso en aquellos casos en que los fines naturales son perseguidos con un grado excesivo de violencia. Por lo tanto, la violencia particular pone en riesgo el monopolio de la violencia por su mera existencia fuera del derecho y no por los fines perseguidos, siendo entonces su condena fruto del impulso de autoconservación del derecho mismo. Aquí aparece la figura del "gran criminal" como claro ejemplo de este choque entre fines naturales y fines de derecho, imagen que no podría existir desde la teoría soreliana de la violencia, en tanto que para el autor francés el sujeto que pone en cuestión el orden de derecho siempre es colectivo, incluso cuando allí se realicen las individualidades que lo componen ${ }^{54}$.

Más adelante, Benjamin pasa a analizar los lugares donde la violencia es todavía permitida por el derecho. En primer lugar, el derecho de huelga, cuya máxima expresión es la huelga general revolucionaria, la cual puede instaurar o modificar el orden legal vigente si trasciende tanto la mera violencia pirata, que siempre persigue algún deseo discrecional, como la huelga libre de violencia, en tanto pura ruptura de relaciones ${ }^{55}$. La huelga proletaria soreliana estaría así permitida y condenada a la vez por la violencia sancionada, precisamente por poner en cuestión las normas vigentes, motivo por el cual el Estado la considerará un abuso y tomará medidas extraordinarias. Lo mismo sucede con el derecho de guerra, el cual abre el espacio para que dentro del derecho mismo potencias exteriores puedan fundar un nuevo derecho. Ambas instancias, la huelga general revolucionaria y la guerra, se basan en las contradicciones prácticas, y no lógicas, del derecho, dando lugar a la posibilidad de que se actualice una de las funciones de la violencia: la fundación de derecho (rechtsetzend $)^{56}$.

Ahora bien, gracias al ejemplo del militarismo, Benjamin pasa de la función de la violencia como fundadora de derecho, en tanto persigue fines naturales, a la función conservadora (rechtserhaltende), en tanto persigue fines de derecho o estatales. Y es aquí donde explicita el segundo eje fundamental de su análisis: la supervivencia de la violencia en el traspaso de un estado de naturaleza hacia un orden de derecho. Vale recordar que, como ejemplos de esta nueva función, Benjamin analiza la pena de muerte y la policía, señalando que en ambas instancias fundación y conservación se confunden ${ }^{57}$. Luego, Benjamin sostiene que si tomamos a la violencia como medio caemos necesariamente en una de estas funciones (o tal vez en ambas), es decir, en una relación ineludible con el derecho. Si la violencia "no aspira a ninguno de estos dos atributos, renuncia por sí misma a toda validez (Geltung)" 58 . Precisamente aquí radica la pregunta del texto, en la posibilidad de una violencia sin validez, que no guarde ningún tipo de relación con el derecho, ya sea existente o prometido.

A continuación, el texto plantea la cuestión sobre la posibilidad de una resolución no violenta de los conflictos, que quedará reducida al ámbito de las relaciones entre personas privadas, para las cuales los medios limpios representarán soluciones mediatas. Incluso el contrato de derecho conserva todavía la violencia que lo funda, ya que se construye direc-

54 Desde ya que la cuestión del proletariado como sujeto revolucionario será fundamental en los fragmentos que componen el texto de Benjamin "Sobre el concepto de la historia", en Conceptos de filosofía de la historia, op. cit., pp. 65-76.

55 Op.cit., p. 118.

56 Op.cit., p. 119.

57 Op.cit., pp. 122-124.

58 Op.cit., p. 124. 
tamente sobre los cimientos que brinda un orden de derecho, volviéndose violento tanto su origen como su resultado. Y aquí, Benjamin afirma que "si decae la conciencia de la presencia latente de la violencia en una institución (Rechtsinstitut), ésta se debilita" 59 . El ejemplo por excelencia es para este autor el parlamento, en tanto carece del sentido de la violencia fundadora de derecho que se halla representada (repräsentiert) en ellos. Como vemos, la crítica al liberalismo es idéntica a la soreliana, en tanto sus instituciones buscan clausurar el conflicto, suturando la escisión con supuestos medios no violentos y haciendo caso omiso de la violencia que las atraviesan ${ }^{60}$.

Cuando Benjamin pasa a detallar el lugar de la regulación no violenta de los conflictos entre personas privadas, afirma que "el acuerdo no violento surge dondequiera que la cultura del corazón pone a disposición de los hombres medios puros de entendimiento"61. La manifestación objetiva de estos medios no violentos está determinada por la ley, en tanto ésta establece que sólo se pueden resolver conflictos entre hombres a través de la intermediación de las cosas. En este sentido, la técnica, cuyo ejemplo privilegiado será para Benjamin la conversación como forma de entendimiento civil, es el campo propio de la resolución no violenta de conflictos. Puede existir un medio puro siempre que se produzca una demora del cara a cara mediante una cosa (no otra persona), que funcionará como elemento neutral a la hora de resolver determinado conflicto. Ahora bien, acto seguido Benjamin señala que la decadencia del derecho lo hace inmiscuirse en esferas donde imperarían los medios puros, precisamente por el temor que le despierta la violencia que podrían ocasionar los medios no violentos como reacción. Y es este mismo debilitamiento el que ha hecho al derecho tolerar el derecho de huelga, precisamente como forma de retardar otras acciones violentas a las que teme oponerse ${ }^{62}$.

En este punto, retomando la cuestión de los medios limpios en política, Benjamin hace propia la distinción soreliana entre la huelga general política y la huelga general proletaria. La primera es violenta en tanto fundadora de derecho, mientras que la segunda es un medio limpio en tanto anarquista ${ }^{63}$. En otras palabras, la primer forma de suspensión del trabajo es violenta en tanto tiene un fin determinado dentro del orden de derecho vigente, incluso cuando pretende modificarlo, mientras que la segunda no busca una reforma de las condiciones de trabajo sino una reinvención de las mismas más allá de la forma estatal, por lo tanto, lejos también de cualquier derecho posible. Y aquí reside una gran diferencia con Sorel, en tanto para Benjamin no es posible calificar de violenta a la huelga general revolucionaria en el mismo sentido en que se lo hace con la huelga general política, incluso cuando puede presentar eventuales consecuencias catastróficas. Afirma que "respecto de la violencia de una acción se puede juzgar tan poco a partir de sus efectos como a partir de sus fines, y que sólo es posible hacerlo a partir de las leyes de sus medios" 64 .

59 Op.cit., p. 125.

60 Ibid.

61 Op.cit., p. 126.

62 Op.cit., p. 127.

63 Op.cit., p. 129.

64 Ibid. 
Parece así quedar escindida la idea de violencia entre la fuerza en sentido soreliano y la noción de medio puro. Por esto, Benjamin nos recuerda que toda solución imaginable a los objetivos humanos debe recurrir a la violencia ${ }^{65}$. Ahora bien, aquí suma a la ya descartada reducción de la violencia a la lógica medio-fin la dificultad a la hora de decidir sobre la conformidad a derecho de los medios y la justicia de los fines. En este sentido, tanto el derecho natural como el positivo, incluso cuando este último había sido rescatado como hipótesis al comienzo de la reflexión, deben abandonarse. Por lo tanto, Benjamin se pregunta nuevamente por la posibilidad de una violencia que no guarde relación con fin alguno, para así poder juzgarla sólo a partir de la ley de sus medios. Aquí encuentra un ejemplo cotidiano de una función no mediada de la violencia, es decir, de una violencia como pura manifestación (Manifestation): la ira. A su vez, Benjamin recurre al mito como forma objetiva de esta violencia, coincidiendo en esta definición nuevamente con Sorel. La violencia mítica sería entonces la pura manifestación de los dioses ${ }^{66}$. El mito soreliano, la huelga general revolucionaria, resultaría ser una forma de violencia como medio puro, pero paradójicamente Benjamin la deja del lado de la violencia-fuerza, precisamente por su afinidad (incluso identidad) con la violencia fundadora de derecho. ¿Por qué esta ambigüedad hacia el mito soreliano? Porque la violencia mítica no es para Benjamin estrictamente destructora, debido a su vínculo con la doble función de la violencia. En primer lugar, vimos que la violencia persigue como fin un derecho que pretende fundar. En segundo lugar, una vez instaurado el nuevo orden de derecho no se renuncia a la violencia. En otras palabras, cualquier manifestación de la violencia puede en última instancia perseguir como fin la instauración de un nuevo orden y la conservación del mismo. Así, fundación de derecho equivale a fundación de poder, señalando aquí Benjamin la distancia entre la justicia como principio de toda fundación divina de fines y el poder como principio de toda fundación mítica de derecho ${ }^{67}$. Sobre las implicancias para el derecho de Estado, Benjamin sostiene que a su dominio corresponde el establecimiento de fronteras y límites, pasando luego a resaltar la identificación de la violencia mítica como manifestación inmediata y toda violencia de derecho. Por lo tanto, surge necesariamente la pregunta por la posibilidad de una violencia inmediata pura que paralice a la violencia mítica: la violencia divina ${ }^{68}$.

Si la violencia mítica funda el derecho, la divina lo destruye, si aquélla establece límites y confines, ésta destruye sin límites; si la violencia mítica culpa y castiga, la divina exculpa; si aquélla es tonante, ésta es fulmínea; si aquélla es sangrienta, ésta es letal sin derramar sangre. [...] La violencia mítica es violencia sangrienta sobre la desnuda vida en nombre de la violencia; la pura violencia divina es violencia sobre toda vida en nombre del viviente. (Die mytische Gewalt ist Blutgewalt über das bloße Leben um ihrer selbst, die göttliche reine Gewalt über alles Leben um des Lebendigen willen) La primera exige sacrificios, la segunda los acepta ${ }^{69}$.

\footnotetext{
65 Op.cit., p. 130.

66 Op. cit., p. 131.

67 Op, cit., p. 132.

68 Op.cit., p. 134.

69 Ibid.
} 
Benjamin argumenta sobre el límite que el "no matarás" presenta, en tanto es distinguible la mera vida natural-biológica (bloße Leben) de la existencia justa (gerechten Dasein). Lo humano no se confunde con la mera vida, por lo tanto la violencia divina acepta los sacrificios que la violencia mítica exige, siempre en vistas a lograr una vida justa ${ }^{70}$.

Finalmente, Benjamin cierra su texto afirmando que la crítica de la violencia es la filosofía de su propia historia ${ }^{71}$. El mesianismo radica en este preciso punto, cuando se postula la llegada de una nueva era histórica que rompa con el ciclo dialéctico y mítico entre violencias fundadora y conservadora de derecho. Y aquí encuentra la tarea fundamental, la de decidir cuándo se trata de una violencia limpia, es decir divina, en cada caso en particular, ya que sólo la mítica resulta clara y evidente a los ojos humanos. Y es esta falta de claridad y evidencia la que vuelve a la violencia divina difícil, o tal vez imposible, de ejemplificar históricamente.

\section{Schmitt y la crítica a la teoría política del mito}

El texto publicado por Schmitt en 1923 bajo el título "La teoría política del mito"72 presenta en sus primeras líneas su interés principal: enfocarse "de manera consecuente en el fundamento ideológico de las tendencias políticas y filosófico-estatales, con el objeto de conocer la situación histórico-intelectual (moralisch) del actual parlamentarismo y la fuerza de la idea parlamentaria"73. De este modo, Schmitt diferencia la dictadura del proletariado marxista, en tanto no desvinculada absolutamente de la posibilidad de una dictadura racionalista, de las doctrinas de la acción directa y el uso de la violencia, basadas en una filosofía de la irracionalidad.

No se trata de un racionalismo que se convierta en lo contrario de sí mismo al entregarse a utopías fantásticas y ser llevado al extremo, sino de una nueva valoración del pensamiento racional en general, de una fe nueva en el instinto y la intuición, que acaba con toda confianza en la discusión y que también rechazaría preparar a la humanidad para ésta por medio de una dictadura educacional ${ }^{74}$.

Y aquí aparece la figura de Sorel, central para el pensamiento político de la época según Wyndham Lewis, a quien Schmitt cita en otro texto de manera aprobatoria ${ }^{75}$. En su lectura de Reflexiones sobre la violencia el jurista alemán encuentra la influencia clara y evidente de Proudhon y Bakunin, quienes se oponen a cualquier tipo de unidad sistemática, ya sea Dios, el Estado, la burocracia, el parlamento, etc. Pero a su vez reivindica el núcleo del pensamiento de Sorel, la teoría del mito, en tanto en ella

70 Op.cit., p. 135.

71 Op.cit., p. 137.

72 Schmitt, C., Die geistesgeschichtliche Lage des heutigen Parlamentarismus, Berlin, Duncker und Humboldt, 1985, pp. 74-79. Aquí, excepto cuando lo indiquemos, seguiremos la traducción "La teoría política del mito", en Carl Schmitt, teólogo de la política, trad. A. Scherp, México, FCE, 2001, pp. 65-81.

73 Op.cit., p. 65.

74 Op. cit., pp. 65-66.

75 Schmitt, Carl, Die geistesgeschichtliche Lage des heutigen Parlamentarismus, Berlin, Duncker und Humboldt, 1985 , p. 86 (nota 51). 
[...] se encarna la oposición más extrema contra el racionalismo absoluto y su dictadura, pero también, por constituir una doctrina de la decisión activa directa, contra el racionalismo relativo del complejo establecido en torno a conceptos como la creación de equilibrio, la discusión pública y el parlamentarismo ${ }^{76}$.

Por lo tanto, si bien la herencia anarquista le prohíbe a Sorel pensar en la posibilidad de una unidad política, su concepción de la violencia como forma no-mediada de decisión lo convierte en un arma poderosa contra el parlamentarismo liberal de la época.

Luego de dedicar varias páginas a la exposición de las líneas fundamentales del pensamiento de Sorel, Schmitt pasa a señalar lo que él llama incoherencias, es decir, contradicciones inorgánicas en la teoría del mito soreliana. La primera y principal crítica será el economicismo, es decir, la herencia que arrastra Sorel con relación a Marx en cuanto a la dependencia del campo de batalla y las armas del enemigo. Afirma en este punto Schmitt que "si se acepta seguir al burgués al terreno económico, habrá que seguirlo también en cuestiones de democracia y parlamentarismo" "77. No es posible, tal como pretendía Sorel, heredar el desarrollo productivo alcanzado por la burguesía, el cual debería ser incluso alentado hasta llegar a su punto máximo de expresión, y despojarse al mismo tiempo de sus instituciones. En este sentido, continuar con la lógica de la producción liberal obligará al proletariado a renunciar a los mitos, "al igual que le sucedió a la burguesía, el predominio del mecanismo de la producción lo empujará a una existencia racional y mecanicista carente de mitos" 78 .

Una segunda contradicción la encuentra Schmitt en la apología de Lenin que Sorel agregara a su texto en la edición de 1919. Allí, Sorel rescata un logro fundamental del proletariado ruso, haber restituido a Rusia su carácter específico. Por lo tanto, esto en boca de Sorel significaría que la energía de lo nacional sería más poderosa que el mito de la lucha de clases. Y aquí aparece Mussolini como el único caso de eliminación de la democracia y el parlamentarismo mediante la apelación al mito nacional, ejemplo de la fuerza irracional del mismo $^{79}$. Schmitt explicita una pregunta que atraviesa el pensamiento de Sorel: ¿es posible un mito de lo nacional más allá de la figura centralizadora del Estado?

Schmitt concluye su ensayo señalando el peligro existente en el irracionalismo anarquista, el cual se traduce desde la perspectiva de la teología política en politeísmo, en tanto excluye cualquier vestigio de unidad, reemplazándolo por un sinnúmero de mitos ${ }^{80}$. Si bien no deja de reconocer su valor en la lucha contra ese enemigo común llamado parlamentarismo, el rechazo de la idea de unidad, con el correspondiente orden que evitaría así la permanencia en el caos de la anarquía, resulta para Schmitt una nueva caída en las redes del liberalismo, cuyo dogma consiste precisamente en la auto-regulación del entramado social a partir de la automática producción y aplicación de la norma.

76 Schmitt, C., "La teoría política del mito", en Carl Schmitt, teólogo de la política, op. cit., p. 67.
77 Op. cit., p. 71.
78 Ibid..
79 Op. cit., p. 73.
80 Op.cit., p. 74.

Daimon. Revista Internacional de Filosofía, nº 67, 2016 
Un desarrollo mayor de esta crítica lo encontramos en el trabajo Catolicismo romano y forma política ${ }^{81}$, publicado en 1923 por Schmitt, en el cual centra su atención en la Iglesia católica como complexio oppositorum, es decir, como unidad de lo heterogéneo, gracias a la estricta aplicación del principio de la representación, por un lado, y la consecuente capacidad para la Forma jurídica, por el otro. En este breve pero fructífero texto Schmitt vuelve sus armas contra el liberalismo, el predominio de la técnica y, por supuesto, el economicismo. Y es aquí donde reaparece la figura de Sorel. En primer lugar, Schmitt señala que el autor francés no es justo con el espíritu del Catolicismo al suponer que ya no tiene la capacidad de crear y creer en sus propios mitos ${ }^{82}$. En segundo término, retoma la crítica ya antes mencionada.

Los financieros americanos y los bolcheviques rusos se encuentran juntos en la lucha por un pensamiento económico, es decir, en la lucha contra los políticos y los juristas. De esta alianza también forma parte Georges Sorel, y es aquí, en el pensamiento económico, donde reside la oposición esencial de nuestro tiempo contra la idea política del Catolicismo ${ }^{83}$.

Sorel comparte entonces con el liberalismo burgués el economicismo. En este sentido, su anti-estatalismo sería coherente con esta perspectiva, en tanto una unidad política tal como la piensa Schmitt siempre se opondría a la lógica técnico-mercantil. Leemos en Schmitt:

[...] el nuevo ordenamiento no puede agotarse en el centro de producción y en los procesos de consumo, porque ese ordenamiento tiene que ser formal, pues todo ordenamiento es un ordenamiento jurídico, como todo Estado es un Estado jurídico o de Derecho ${ }^{84}$.

La inmanencia técnico-económica sólo puede producir un automatismo que se engaña al no reconocer que en última instancia también necesita de un ordenamiento jurídico previo para poder desarrollarse. En este sentido, no puede haber orden sin unidad político-jurídica. Nuevamente, el riesgo del politeísmo anarquista soreliano es el de dejar el campo abierto a la lógica liberal y su ocultamiento del orden y la unidad que le sirven de condición de posibilidad para su desarrollo.

\section{Lecturas encontradas}

Son muchos los ejes abiertos en el diálogo entre Benjamin y Schmitt a partir de su lectura de Sorel. A modo de cierre intentaremos explicitar algunos de ellos, los que aquí consideramos más importantes, con el propósito de evidenciar sus irreconciliables posicionamientos

81 Schmitt, C., Römischer Katholizismus und politische Form, Hellerau, Jakob Hegner, 1923. Las citas, excepto en los casos indicados, serán tomadas de la traducción Catolicismo y forma política, trad. C. Ruiz Miguel, Bs. As., Areté, 2009.

82 Op.cit., p. 62.

83 Op.cit., p. 60.

84 Op.cit., p. 74. 
políticos. Desde ya que el primer punto, que atraviesa todos los demás, no puede ser otro más que el del mito. Por el lado de Schmitt aparece la reivindicación del mito como fuerza que interrumpe el normal desarrollo de la lógica liberal, pero desde su perspectiva este mito debe ser el de lo nacional, el cual ya estaba anunciado en Sorel. Está claro que en el caso del autor francés si existe la posibilidad de presentar a lo nacional como un mito que conduzca a la destrucción de todo orden, este debe quedar escindido de una unidad estatal. En este sentido, lo nacional parecería no estar ligado directamente a la posibilidad de una unidad política determinada a partir de la cual construir un nuevo orden. Si esto es así, Schmitt se encarga de dejar muy en claro el riesgo que se corre de sentar las bases para la proliferación del imperio liberal, el cual en última instancia oculta el ordenamiento político que lo subyace. Así también se hace comprensible la crítica que el propio Benjamin realiza a la violencia mítica soreliana, en tanto inseparable de la fuerza fundadora y conservadora de derecho. Volviendo a Schmitt, Müller sostiene que éste privilegia el mito nacional por cuestiones histórico-fácticas, en tanto la lucha de clases no tendría la misma efectividad a la hora de iluminar la distinción entre amigos y enemigos ${ }^{85}$. Para este comentarista, lo que hemos llamado el carácter "fenomenológico" del mito sería precisamente lo que haría a Schmitt adoptar el mito nacional como ejemplar, desde ya que acompañado de la idea de unidad que la nación implica. Si hay algo que queda explicitado en el pensamiento del jurista alemán es precisamente su rechazo al politeísmo político que una teoría como la de Sorel (y Benjamin) habilitaría, precisamente porque en el fondo no haría más que ocultar el monoteísmo mercantil.

Por el lado de Benjamin, su lectura del mito soreliano resulta más enigmática. En principio su relación con la teoría de Sorel parece ser de pura afinidad, sobre todo a la hora de también él destacar la capacidad del mito de interrumpir el desarrollo mecánico de la norma liberal. Sin embargo, cuando surge la distinción entre violencia mítica y violencia divina, quedando la primera ligada directamente al derecho, encontramos un alejamiento del pensador francés. Si bien la revolución proletaria tiene la capacidad de destruir, no es seguro que carezca de todo fin al que considere justo, es decir, no podemos nunca reconocer allí la actualización de la violencia divina y, por ende, resulta imposible asegurar que ese mismo acto destructivo no conducirá a la instauración de un nuevo orden ${ }^{86}$. En este sentido, Benjamin se acercaría a la lectura schmittiana, en tanto la violencia anárquica podría sentar las bases de un nuevo ordenamiento político, incluso de uno disimulado como el liberal. Al mismo tiempo, se posiciona en la rivera opuesta a la de Schmitt, ya que el jurista alemán

85 Müller, J.W., «Myth, law and order: Schmitt and Benjamin read reflections on violence», op. cit., p. 463.

86 Sólo a modo de sugerencia nos permitimos aquí establecer un paralelismo con la ética kantiana tal como aparece desarrollada en la Fundamentación de la metafísica de las costumbres. Allí leemos que una acción tiene valor moral cuando se realiza por el deber y sin perseguir un fin determinado, pero es el propio Kant quien señala que tal vez no sea posible encontrar un ejemplo de dicha acción, ya que en última instancia resulta imposible determinar la pureza de esa "buena" voluntad. Siguiendo con el paralelismo, también cabe aquí señalar la cercanía entre la crítica de Derrida a Benjamin y la que Hegel realiza al imperativo categórico kantiano. Si el criterio para reconocer una acción con valor moral o la violencia divina es meramente formal, se corre el riesgo del terror, es decir, de poder colocar cualquier caso histórico como ético o como expresión de esa violencia divina. Kant, I., Fundamentación de la metafísica de las costumbres, trad. M. García Morente, México, Porrúa, 1995. Derrida, J., Fuerza de ley, trad. A. Barberá y P. Peñalver Gómez, Madrid, Tecnos, 1997. Hegel, G. W., Principios de la filosofía del derecho, trad. J. L. Vermal, Bs. As., Sudamericana, 1975. 
solicita la explicitación de la unidad política, mientras que para Benjamin lo que se busca es la imposible ruptura de la dialéctica entre fundación y conservación de derecho, gracias a la improbable violencia divina.

Otro punto fundamental de este debate también es señalado por Müller, para quien la violencia en el caso de Schmitt caería bajo una lógica instrumental, en tanto la decisión como momento excepcional que rompe con el curso automático de las cosas busca siempre fundar un nuevo orden bajo la unidad Estatal, mientras que en el caso de Benjamin nos encontraríamos con una violencia nihilista que no persigue fin alguno más que la destrucción total de cualquier orden ${ }^{87}$. Resulta claro, por lo dicho más arriba, que cada uno colocaría a Sorel en la vereda opuesta, en tanto para Schmitt la violencia mítica propuesta en Reflexiones sobre la volencia busca sólo interrumpir el orden de las cosas pero no construir uno nuevo (al menos no de manera declarada), mientras que para Benjamin nunca podríamos asegurarnos de la falta absoluta de finalidad. Müller concluye que ambos pensadores son anti-políticos, en el caso de Benjamin por su rechazo explícito de la política, por el lado de Schmitt por la total sumisión del individuo a la homogeneidad de la unidad política ${ }^{88}$. Por nuestra parte, creemos que esta lectura es algo controvertida, en tanto Benjamin está reconociendo la necesidad de la violencia mítica y la dificultad que plantea la divina a la hora de pensar su manifestación. Por el lado de Schmitt, el lugar de la diferencia, y por lo tanto de la singularidad, está dado dentro de un ordenamiento político, ya que el "caos" liberal no produce más que homogeneidad bajo la aplicación mecánica de la norma. Sería, tal vez, un punto más de acercamiento con la teoría soreliana, para la cual la individualidad encuentra su realización en la masa como sujeto histórico.

Otro eje es el analizado por Villacañas y García: la figura del mesías. Aquí la diferencia radica en la ruptura o no entre un tiempo mesiánico y el tiempo histórico. Sostienen los autores que para Schmitt el soberano garantiza la continuidad del tiempo para resguardar el mundo que el Mesías necesita al momento de su llegada, mientras que en Benjamin esta posición recaería en un nuevo mito ${ }^{89}$. Sin embargo, Benjamin también sucumbiría en la teocracia schmittiana al plantear una radical escisión entre lo mundano y lo divino, es decir, entre la historia y lo mesiánico ${ }^{90}$. En la historia no habría nada más que mitos, mientras que lo mesiánico se encontraría siempre por venir. De alguna manera, nuestra hipótesis de lectura es afin con esta interpretación. Si bien Benjamin parecería centrarse en la posibilidad de romper con la lógica fundación-conservación de derecho, esa violencia divina se encontraría siempre en un porvenir indeterminado que, mientras tanto, nos deja a merced de la historia. Desde aquí, puede pensarse a Benjamin también como un pensador de lo teológico-polítco, algo que en Schmitt es más que evidente pero que de ninguna forma podríamos afirmar de Sorel.

87 Müller, J.W., «Myth, law and order: Schmitt and Benjamin read reflections on violence», op. cit., p. 470.

88 Op.cit., p. 472.

89 Villacañas, J. L. y García, R., "Walter Benjamin y Carl Schmitt: Soberanía y Estado de Excepción”, op. cit., p. 50.

90 Op.cit., p. 58. 
